\title{
Educação no Modo de Produção Capitalista: as influências sofridas pelo sistema ${ }^{1}$
}

\author{
Morgana Zardo von Mecheln ${ }^{1}$, Samira de Moraes Maia Vigano ${ }^{2}$ e \\ Maria Hermínia Lage Fernandes Laffin ${ }^{3}$
}

1 Doutoranda do Programa de Pós-Graduação em Educação pela Universidade Federal de Santa Catarina e Mestra em Educação pela UFSC, Brasil. E-mail: vonmechel@gmail.com

2 Doutoranda do Programa de Pós-Graduação em Educação pela Universidade Federal de Santa Catarina e Mestra em Educação pela UFSC, Brasil. E-mail: samirammvigano@gmail.com

3 Pós-Doutora pela Universidade do Estado da Bahia. Doutora em Educação pela Universidade Federal de Santa Catarina Professora do Curso de Pedagogia e do Programa de Pós-Graduação em Educação da Universidade Federal de Santa Catarina, Brasil. E-mail: herminialaffin@gmail.com

RESUMO: O artigo refere-se ao estudo das teorias da Administração como influenciadoras dos processos educativos humanos, com ênfase à formação dos trabalhadores e à preparação de homens qualificados a determinado sistema produtivo: o capitalismo. O objetivo da pesquisa foi de evidenciar, por meio de um estudo de cunho teórico metodológico, que os pensadores e estudos da área da Administração impactam nas questões que se referem à formação escolarizada do trabalhador, e que tais influências se mantêm até os dias atuais. Para o aporte teórico foram utilizados autores como Marx (2013), Harvey (2013), Fayol (1994) e Taylor (1990). O estudo mostrou que as necessidades do mercado de trabalho ainda direcionam os processos educativos como no início do século passado, agora camufladas pelas determinações dadas com nomes de competências. Conclui-se que a constituição de um ser humano integral ainda requer estudos, lutas e pressões dos movimentos populares da sociedade civil que façam frente a essas deliberações pautadas na fragmentação do trabalhador.

Palavras-chave: Modo de Produção Capitalista. Teorias administrativas. Educação do trabalhador.

Education in Capitalist Mode of Production: the influences suffered by the system

ABSTRACT: The article refers to the study of Management theories as influencers of human educational processes, with emphasis on the workers formation and the preparation of qualified men to a certain production system: the capitalism. The objective of the research was to highlight, through a theoretical methodological study, that thinkers and studies in the area of Administration impact on the issues that refer to the schooling of workers, and that such influences remain until the present days. For the theoretical contribution authors were used Marx (2013), Harvey (2013), Fayol (1994) and Taylor (1990). The study showed that the labor market needs still direct the educational process as early last century, now camouflaged by the determinations with names of competencies. In conclusion, the constitution of an integral human being still requires studies, struggles and pressures of the popular movements of the civil society that face these deliberations based on the fragmentation of the worker.

Keywords: Capitalist mode of production. Management theories. Worker education.

${ }^{1}$ Este trabalho é resultante de parte da pesquisa de mestrado intitulada "A Compreensão de Trabalho dos Professores do PROEJA-FIC: contexto da parceria SME e Escola Canto da Ilha/CUT, Florianópolis", de Morgana Zardo von Mecheln, defendida no ano de 2015. 


\section{INTRODUÇÃO}

$\mathrm{O}$ artigo refere-se ao estudo das teorias da Administração como influenciadoras dos processos educativos humanos, com ênfase à formação dos trabalhadores e à preparação de homens qualificados a determinado sistema produtivo: o capitalismo.

O objetivo da pesquisa foi de evidenciar, por meio de um estudo de cunho teórico metodológico, que os pensadores e estudos da área da Administração impactam nas questões que se referem à formação escolarizada do trabalhador, principalmente a partir da segunda fase da Revolução Industrial, e que tais influências se mantêm até os dias atuais.

O recorte trazido nesse artigo pretende contextualizar como historicamente o sistema capitalista influenciou a educação, principalmente da classe trabalhadora, e como isso foi incorporado através dos tempos. Justifica-se a escolha dessa temática, que mesmo sendo histórica, apresenta-se como atual para a discussão da educação atual, em que se faz presente estruturas dominantes que tendem a rever processos impositivos, que geram uma classe omissa e sem posicionamento crítico.

Baseia-se em uma percepção da burguesia como detentora dos meios produtivos. Essa burguesia ${ }^{2}$ aqui retratada conseguiu se desenvolver e se estabelecer como classe dominante na sociedade moderna. Essa dominância acontece, pois, para Marx e

\footnotetext{
2 Atualmente a burguesia (a classe burguesa, ou capitalista) deve ser compreendida de forma mais ampla, englobando: os proprietários de terras (capital fundiário), dos meios de produção (capital industrial), dos meios de consumo (capital comercial) e das instituições de intermediação financeira (capital bancário) (MONTAÑO; DURIGUETTO, 2011).
}

Engels (2010), cada etapa do desenvolvimento da burguesia é acompanhada por um progresso político que a corresponde. Ou seja, a burguesia está imbricada com os processos políticos da época e assim consegue determinar as ações que deseja implementar na sociedade. Marx e Engels (2010) são firmes quando denunciam que o governo do Estado moderno é tão somente um comitê para gerir os negócios de toda essa burguesia.

De acordo com Kuenzer (1988), se a divisão do trabalho (social e técnica) é condição para a constituição do Modo de Produção Capitalista (MPC), na medida em que é rompida a unidade entre teoria e prática. Os homens são preparados diferentemente para que atuem em posições hierárquicas e tecnicamente diferenciadas no sistema produtivo; deve-se admitir, então, como um processo natural a constituição de sistemas de educação marcados por essa dualidade estrutural. Essa dualidade se evidencia na escola quando, ao assumir como seu conteúdo a pauta ditada pela desigualdade social e regulamentada pela lei, passa a ser um eficiente mecanismo na legitimação das desigualdades estruturalmente produzidas na sociedade (NORONHA, 2004).

A história da educação para o povo gira em torno do binômio: permitir sua instrução e reprimir sua educação-formação, ao qual, tem de um lado a burguesia que defende que todos saibam ler, escrever e contar, ou seja, democratizar a instrução elementar; e de outro lado, não permitir que os trabalhadores ${ }^{\frac{3}{3}}$ sejam esclarecidos, con-

\footnotetext{
3 Nos dias de hoje, a classe trabalhadora é formada por trabalhadores do chão de fábrica, de setores administrativos e de serviços no setor industrial, servidores públicos, autônomos, balconistas de comércio, funcionários de organizações civis, podem ter contratos tem-
} 
trolando sua formação, mantê-los na ignorância a fim de serem guiados pelos capitalistas esclarecidos - controlar, reprimir o saber, e também a educação e organização da classe trabalhadora (ARROYO, 2012).

Embora pareça importante, a educação dos trabalhadores não pode ser aquela que permita o pensamento livre, o capital requer certos tipos de aptidões, mas tem horror a toda aptidão que o trabalhador possa monopolizar (HARVEY, 2013). Isso quer dizer que aos trabalhadores é pensada um modo de educação determinada pelo modo de produção vigente.

No MPC quem determina a finalidade do trabalho é o capital, assim "o tempo de trabalho, o local, o ritmo, o horário e o controle são definidos pelo capital, personificado no patrão; é preciso produzir o trabalhador para o capital (disciplinamento da força de trabalho). E um dos locais legítimos para esse disciplinamento ${ }^{4}$ é a escola" (NORONHA, 2004, p. 51). A escola, por isso, foi se desenvolvendo em sintonia com o modo de produção.

\section{DIVISÃO DO TRABALHO, DIVISÃO DA EDUCAÇÃO}

porários ou estáveis, ganhar salário fixo ou comissão, com direitos trabalhistas ou não, podem representar o setor mais empobrecido da população, grupos de consumo médio, ou ter um elevado padrão de vida, podem possuir força de trabalho desqualificada ou altamente qualificada, resumindo: o que determina que o sujeito pertença à classe trabalhadora é precisar vender sua força de trabalho para sobreviver (MONTAÑO; DURIGUETTO, 2011).

4 Noronha usa aqui o termo "disciplinamento" no sentido de coerção, de adaptar os sujeitos ao ambiente existente, diferente do sentido gramsciano, que toma a palavra disciplina numa compreensão positiva. Nosella (2004) explica que Gramsci articula a disciplina externa impositiva, com a autodisciplina e exercícios de autonomia, educando para superar o ambiente existente.
No início do século XX, Fayol (1994) $\stackrel{5}{a}$ acreditava que era necessário promover a divisão do trabalho, ou seja, fazer o trabaIhador desenvolver atividades fracionadas e deixar de ter o conhecimento de todo o processo produtivo ${ }^{\underline{6}}$. Essa divisão do trabaIho tem por objetivo produzir mais e meIhor, com o mesmo esforço (FAYOL, 1994). Por conseguinte, esse modelo de divisão foi transposto para a escola, que se distanciou ainda mais de uma formação integral dos sujeitos para oferecer conteúdos fragmentados em disciplinas, preparando a mão de obra para o mercado de trabalho: sujeitos fragmentados.

Marx (2013) usa a expressão trabalhadores parciais quando escreve que a divisão do trabalho supõe a autoridade incondicional do capitalista sobre homens que constituem as engrenagens de um mecanismo total que a ele pertence. Essa parcialidade é a negação à totalidade do sujeito, da integralidade do trabalho. Com as mudanças nos processos produtivos "o trabalho exige do homem cada vez menos habilidades das mãos e cada vez mais a livre disponibilidade do corpo" (NOSELLA, 2012, p. 45).

Harvey (2011) adverte, porém, que na luta de classes não é apenas o trabalhador

\footnotetext{
${ }^{5}$ Henri Fayol é um dos teóricos clássicos da Ciência da Administração. Foi o fundador da Teoria Clássica da Administração fornecendo um método científico à área que, até então, era apenas empírica. Sua mais importante obra é Administração Industrial e Geral, publicada a primeira vez em 1916. Seus estudos convergem para a estrutura das organizações e a busca pela máxima eficiência dos processos (MORETTO NETO; SCHMITT, 2011). Os conceitos da Administração foram muito influentes na administração pública mundial, aqui no Brasil começou a se tornar evidente nos mandatos de Fernando Henrique Cardoso e suas políticas públicas instituídas.

${ }^{6}$ Hoje ainda há essa ordem-processo, mas sob o discurso da flexibilidade, que será discutido adiante.
} 
que luta contra a exploração do capital, é também o capitalista que luta bravamente para tornar o trabalho servil, para tornar o trabalhador subserviente. Para produzir o capital, as relações sociais são moldadas de forma colaborativa e cooperativa, às vezes isso é alcançado pela força bruta, pela coação, mas mais usualmente é alcançado pelas formas de organização social que implicam confiança, lealdade e formas sutis de dependência, e isso ocorre nas relações sociais no chão de fábrica, nos campos, nos escritórios, instituições, agindo nas redes de transporte, na comunicação e, claro, na educação (HARVEY, 2011).

Nas proposições de Fayol (1994) era preciso doutrinar os trabalhadores a alguns princípios para o bom funcionamento das empresas: divisão do trabalho, autoridade, responsabilidade, disciplina, subordinação do interesse particular ao interesse geral, hierarquia, ordem, iniciativa, entre outros. "É necessário, pois, esforçar-se para inculcar as noções administrativas em todas as classes sociais. A escola desempenhará, evidentemente, papel considerável nesse ensino" (FAYOL, 1994, p. 39). A escola então deveria ser modernizada para ajudar no desenvolvimento de um novo homem, cada vez mais adaptado à indústria em ampla expansão da época.

Nesses momentos, para Noronha (2004), é interessante observar que há convergência entre os interesses das classes que até então pareciam ser antagônicos, como a luta pela educação, porém, essa luta secular da classe trabalhadora pela escola não busca, necessariamente, o conhecimento historicamente acumulado pela burguesia, a luta implica na crítica radical ao saber dominante, haja vista, uma articulação do conhecimento histórico (que é uma produção de toda a sociedade, não exclusividade da burguesia) aos interesses da classe trabalhadora, trata-se então, de uma nova forma de produção do conhecimento (FRIGOTTO, 2012).

Porém, o proletariado não conquista a consciência de classe apenas operando sobre si, mas conquista-a, fazendo política, o que significa que o trabalhador em geral não chega espontaneamente à consciência política, sendo fundamental, portanto, a educação, sobretudo a educação política (GADOTTI, 2012). Como escreve Sánchez Vázquez (2011), é impossível à consciência comum, abandonada a si mesma, superar sua concepção espontânea e irreflexiva da prática e elevar-se a outra concepção. Para essa mudança de concepção é preciso estímulo, impulso externo e a educação pode ser um dos meios.

Porém, Arrovo (2012) entende que a garantia do direito à educação não passou de uma proposta repetida por educadores e exigida pelo povo, enquanto a burguesia parece acreditar que é mais difícil explorar um trabalhador que sabe ler do que um analfabeto. Assim, continua Arroyo (2012), frente a uma visão depreciativa para com os trabalhadores, encontramos uma história de pressão por parte do povo, dos educadores, pelo direito não apenas a ser instruído, mas a ser esclarecido, ser reconhecida sua capacidade de pensar, decidir sua sorte, ser sujeito de saber e de cultura, a luta maior pelo direito à educação entendida em sentindo amplo.

A seguir, historicizamos como se desenvolve o processo da educação dos trabalhadores e a constante luta da burguesia pela excelência do capitalismo, e a luta dos trabalhadores por condições dignas de sobreviver nesse sistema e, quem sabe, refletir 
circunstâncias para superá-lo.

\section{EDUCAÇÃO PARA O TRABALHADOR}

$O$ século $X X$ abriu suas portas a um dos períodos mais marcantes da história da sociedade, apresentando um alto desenvolvimento tecnológico que impactou no aumento significativo da capacidade produtiva da indústria, "marcas dessa revolução são a máquina elétrica e o motor a explosão, o uso de aço e materiais sintéticos, o petróleo e a energia elétrica" (MONTAÑO; DURIGUETTO, 2011, p. 157).

A máquina sempre foi o sonho de libertação do homem, fazer com que o ser humano poupasse suas mãos, livrá-las dos calos grossos e duros para levemente segurar o pincel da pintura ou o lápis do desenho e da poesia, ou ainda soltá-las para os movimentos da dança e da música; a máquina, obra da inteligência humana, poderia finalmente reduzir a jornada de trabalho transformando o homem em cidadão político, culto e artista (NOSELLA, 2012).

Para um novo modo de produção foi preciso formar uma nova mão de obra que atendesse às demandas da moderna indústria, que se desenvolvia a passos largos, impulsionada pela tecnologia. E a tão sonhada liberdade, teve que aguardar.

Fayol (1994), escrevendo sobre esse período histórico, afirmou que ninguém poderia duvidar que um bom ensino primário fosse uma excelente preparação para os trabalhos industriais. Fayol (1994) insistia que a escola era um espaço de preparação de trabalhadores para a indústria, desde o trabalhador operário, do contramestre, até do trabalhador engenheiro e diretor. Com relação ao ensino de engenharia, chamado de ensino técnico superior, Fayol (1994), a seu ver, acreditava que poderia ser dirigido de maneira mais útil às necessidades da indústria, o que não estaria acontecendo naquele momento. A escola, então, era destinada à indústria e de forma alguma ao propósito de educar.

Ainda no início do século XX, Taylor (1990, sem grifo no original) ${ }^{?}$ procurava por homens eficientes, ou seja, homens melhores e mais capazes, desde diretores de grandes companhias até o mais simples servente. O caminho da eficiência nacional só seria adentrado quando a indústria, as organizações produtivas, compreendessem que é delas a obrigação de cooperar sistematicamente no treinamento e formação dessas pessoas, considerando o interesse delas nesse processo (TAYLOR, 1990).

Com os princípios de Fayol e Taylor, Henry Ford ${ }^{8}$ implementou, na década de 1910, a jornada de 8 horas de trabalho pelo valor de 5 dólares, com a expectativa de obrigar o

\footnotetext{
${ }^{7}$ Frederick Taylor escreveu o livro Princípios de Administração Científica em 1911. Propôs métodos científicos para a administração de empresas e hoje é considerado o pai da administração científica. Para Gerencer (1990), Taylor contribuiu realmente para a indústria com seu método científico quando substituiu processos rotineiros por outros deduzidos de análises; foi o precursor da ciência da direção e, ao mesmo tempo, descobridor da aplicação da ciência àquela fase da produção que afeta intimamente o trabalhador. Enfim, Gerencer (1990, grifo do autor) acredita que Taylor de fato foi o "Pai da Organização Científica do Trabalho". Com minha experiência em estudos da Administração, acredito que Taylor tenha elaborado um método que subjugou ainda mais o trabalhador ao maquinário que estava em pleno desenvolvimento na época.

${ }^{8}$ Henry Ford foi um industrial americano que aplicou em sua empresa de automóveis, a Ford Motor Company, a produção em série na linha de montagem. Com a baixa do tempo e do custo de produção, o automóvel pode ser popularizado nos Estados Unidos (MORETTO NETO; SCHMITT, 2011). Hoje, esse sistema de produção em série é conhecido como fordismo, devido sua abrangência no modo de produção mundial no século XX.
}

https://periodicos.unifap.br/index.php/estacao Macapá, v. 6, n. 3, p. 51-61, set./dez. 2016 
trabalhador a adquirir disciplina e dar-lhe renda e tempo para que pudesse consumir (MONTAÑO; DURIGUETTO, 2011). A estratégia adotada foi tornar o sujeito, além de um empregado, um consumidor dos produtos, além de atrelar sua remuneração à quantidade de horas trabalhadas.

Taylor estudou tão minuciosamente todos os aspectos do trabalhador, que dedicou alguns subcapítulos de seu livro Princípios de Administração Científica para abordar o que ele chamou de vadiagem no trabalho. Segundo Taylor (1990), o grande esforço despendido na prática de um esporte como o basquete, faz com que o trabalhador, no dia seguinte à partida, não empregue todo o seu esforço para produzir a maior soma possível de trabalho, acaba por produzir apenas a metade do que é capaz, ocorrendo assim, a vadiagem no trabalho. A diversão do sujeito, de acordo com essa perspectiva, é um empecilho para o trabaIho e, consequentemente, um perigo para a produção industrial.

Desse modo, o trabalhador passa a ser responsabilizado e estigmatizado, pois é a "vadiagem no trabalho, que diretamente afeta o salário, a prosperidade e a vida de quase todos os trabalhadores, bem como a prosperidade das indústrias nacionais" (TAYLOR, 1990, p. 27, grifo do autor), afetando sua empregabilidade. Nesse caso, entende-se '“empregabilidade' é o eufemismo da desigualdade estrutural que caracteriza o mercado de trabalho e que sintetiza a incapacidade - também estrutural da educação em cumprir sua promessa integradora numa sociedade democrática" (GENTILI, 2002, p. 52, grifo do autor). A empregabilidade do sujeito passa ser a nova lógica após a morte da promessa do pleno emprego, restará ao próprio indivíduo defi- nir suas opções e escolhas que permitam (ou não) conquistar uma posição competitiva no mercado de trabalho (GENTILI, 2002).

Em outras palavras, é o próprio sujeito que passa a ser responsável por se tornar atrativo ao mercado de trabalho, competindo com outros sujeitos que, como ele, são trabalhadores, pertencem à mesma classe, precisam vender sua força de trabaIho para viver e são levados a se destacar dos demais concorrentes para aumentar a possibilidade de se tornar empregado.

Cabe aqui ressaltar que mesmo não empregado, o sujeito ainda é trabalhador. Montaño e Duriguetto (2011) explicam que vender sua força de trabalho converte o trabalhador em empregado; não vender sua força de trabalho converte o trabalhador em desempregado, portanto, desempregado, mas trabalhador. Trabalhador é uma classe que independe da disponibilidade de emprego.

Os planos e ações desses empresários e pensadores mudaram de modo significativo os processos produtivos, como por exemplo, na criação da linha de montagem em séries, que imobiliza o trabalhador fazendo com que os insumos necessários ao desenvolvimento de sua tarefa cheguem às suas mãos, determinando o tempo exato de sua atividade e obrigando o desempenho contínuo de uma única, simples e idêntica tarefa (MONTAÑO; DURIGUETTO, 2011).

Para Harvey (2011), um dos tópicos da história da inovação tecnológica é o esforço de enfraquecer o trabalhador e passar os poderes de movimento e decisão para dentro da máquina, ou em alguma sala com controle remoto. $E$ foi isso que passou a acontecer progressivamente a partir da revolução industrial e se intensificou com os modelos taylorista e fordista de produção. 
Assim, nesse momento histórico, era preciso, além de alfabetizar, educar o povo para a racionalidade imposta pela lógica da produção, então a escola passa a cumprir um papel importante nesse controle como elemento preventivo e disciplinador: ensino profissional, orientação vocacional, organização racional do trabalho (NORONHA, 2004). A escola vai privilegiar a formação profissional para os trabalhadores - com cursos profissionalizantes para atender a demanda de uma nova indústria na cidade, por exemplo -, e a formação humanística para a elite - por exemplo, o estudo da filosofia, das artes, da música, da astronomia.

Essa questão do desigual sistema de promoção da educação fica evidenciada nas propostas de estratificação da classe trabaIhadora e no completo desprezo pelos sujeitos como seres integrais. Nos estudos de Taylor,

Um dos primeiros requisitos para um indivíduo que queira carregar lingotes de ferro [barra de metal fundido] como ocupação regular é ser tão estúpido e fleumático [insensível ao sofrimento] que mais se assemelhe em sua constituição mental a um boi ${ }^{9}$, que a qualquer outra coisa. Um homem de reações vivas e inteligentes é, por isso mesmo, inteiramente impróprio para tarefa tão monótona. No entanto, o trabalhador mais adequado para o carregamento de lingotes é incapaz de entender a ciência que regula a execução desse trabalho. É tão rude que a palavra percentagem não tem nenhuma significação para ele e, por conseguinte, deve ser treinado por homem mais inteligente no hábito de trabalhar de acordo com as leis dessa ciência, para que possa ser bem sucedido (TAYLOR, 1990, p. 53).

9 "[...] a economia nacional conhece o trabalhador apenas como animal de trabalho, como uma besta reduzida às mais estritas necessidades corporais" (MARX, 2010, p. 31).
Então, com esses discursos, vão se constituindo as noções de que a classe trabalhadora é inferior (mesmo que em diversos níveis) e precisa ser formada para ter empregabilidade no Modo de Produção Capitalista. De modo geral, as classes populares ficam sob a influência da cultura hegemôni$\mathrm{ca}^{10}$, pois ela é, de certo modo, a cultura que funciona como tal por meio da alfabetização, a própria construção da língua nacional pertence à elite educada e o verdadeiro processo de leitura e educação difunde-a, mesmo sem a intenção (HOBSBAWM, 2000).

E foi essa hegemonia da classe dominante que, na forma da educação, assumiu a tarefa de aprimorar a força de trabalho humano, em uma educação que se preocupa com a formação da mão de obra com o intuito de torná-la mais adequada às novas funções nas fábricas e nos serviços modernos (NOSELLA, 2012).

\section{DA LINHA DE PRODUÇÃO À PRODUÇÃO FLEXÍVEL}

O Modo de Produção Capitalista está em constante mutação, sempre se reinventado e os processos administrativos de Taylor, Fayol e Ford tornaram-se obsoletos a partir da década de 1980, com a resistência operária, a globalização ${ }^{\underline{11}}$ do mercado consu-

\footnotetext{
10 "A hegemonia da classe dominante supõe que esta classe produza seus intelectuais, cuja função é garantir o consenso da sociedade" (GADOTTI, 2012, p. 76).

${ }^{11}$ Globalização aqui entendida como uma profunda reorganização do capitalismo, como um processo de produção de desenvolvimento temporal e geográfico desigual, tornando populações inteiras vulneráveis à redução de níveis funcionais, ao desemprego, ao colapso dos serviços, à degradação dos padrões de vida e à perda de recursos ambientais, ao mesmo tempo em que concentra riqueza e poder promovendo oportunidades político-econômicas em poucas e seletivas loca-
} 
midor, as crises do petróleo, o encarecimento das matérias-primas (SHIROMA, 1996). Para Ribas (1998), ocorreram então, importantes alterações na composição orgânica do capital, com o advento de tecnologias baseadas na microeletrônica, na robótica, na computação e dos novos materiais, fazendo aparecer as indústrias de produção flexível $\underline{12}$. É desenvolvido então, um sistema que envolve menores investimentos, menores volumes de trabalhadores estáveis e mais baratos, menos conflitos e estoques reduzidos, um processo produtivo flexível o bastante para se adaptar às flutuações do mercado (MONTAÑO; DURIGUETTO, 2011).

Evidentemente, o trabalhador teve que se adaptar às novas exigências tornando-se também flexível. Shiroma (1996) escreve que a flexibilidade funcional é a possibilidade da empresa usar as habilidades dos trabalhadores nas mais diversas funções (não apenas uma única e repetitiva função como acontecia no fordismo), e para que isso seja possível, espera-se que os trabalhadores tenham múltiplas qualificações - mecânica, eletrônica, administração, custos, vendas e disposição para ensiná-las aos colegas.

Na produção flexível, ou toyotismo, é i-

lidades e em restritos estratos da população (HARVEY, 2013).

${ }^{12}$ Esse novo modelo de produção flexível ficou conhecido como toyotismo, pois foi desenvolvido na empresa automobilística Toyota no Japão. O toyotismo tem como propósito a redução de custo através da completa eliminação de desperdícios, tendo como princípio a manutenção do fluxo contínuo dos produtos manufaturados, com flexibilidade para se adequar às alterações de demanda (SHIROMA, 1996). Esse modelo diferencia-se do fordismo, pois esse produzia permanentemente, em série, grandes volumes que possibilitavam que os preços ficassem baixos, enquanto no toyotismo a produção passou a ser de acordo com a demanda de consumo, ou seja, períodos de grande, média e baixa produção, influenciando na sazonalidade dos empregos. naugurada uma modalidade de adestramento da força de trabalho, com a novidade de que agora para a reprodução do capital, são subordinados os saberes, a arte, a inventividade do operário (RIBAS, 1998). Diferente do fordismo e taylorismo que exigiam mãos, braços, corpos, a produção flexível agrega, além disso, a criatividade, as ideias, a colaboração, a parceria, a liderança, a proatividade do trabalhador. É o que Laffin (2012, grifo do autor) chama de obsoletização do esforço físico, quando se chegou a cogitar que uma mera substituição do esforço físico pela máquina seria uma alternativa possível à condição humana, e que o sujeito conseguisse aproveitar sua capacidade criativa na elaboração de outras atividades superiores à mecanização.

Isso quer dizer que, como escreveu Harvey (2013), os trabalhadores continuam necessariamente alienados porque suas capacidades criadoras são apropriadas pelos capitalistas, do mesmo modo como sua força de trabalho.

Assim, as mudanças passaram a ser rápidas nos requisitos de qualidade de trabalho, como a súbita necessidade de novas habilidades, por exemplo, a alfabetização eletrônica, ao passo que o sistema educacional encontra dificuldade em se adaptar à necessidade permanente de muitas reciclagens na vida de um trabalhador (HARVEY, 2011). O autor ainda aponta que a desqualificação e requalificação, apoiadas pelo desemprego tecnologicamente induzido, produz a precariedade crônica do trabalho. Isso significa que o sujeito nunca está pronto, está sempre inacabado, há sempre novas tecnologias e processos de trabalho a serem apreendidos.

A indústria e o grande mercado internacional continuam hoje a exercer influência 
na educação. A nova alternativa à administração dos trabalhadores é a Gestão por Competência, definida por Girardi e Dalmau

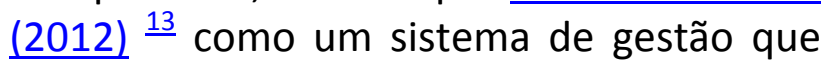
guia o recrutamento, a seleção, o treinamento, etc, para a capacitação e desenvolvimento das competências necessárias para que os objetivos da empresa sejam atendidos.

As competências ganharam tanto destaque que permeiam massivamente os documentos dos organismos internacionais para a educação. O termo competência permeia todo o texto que apresenta avaliações de políticas nacionais de educação com ênfase no Estado de Santa Catarina, descritas nos excertos que seguem:

(...) um dos principais objetivos no longo prazo é a melhora do desempenho dos alunos em todos os níveis do sistema educacional, que, no momento, não os está dotando das capacidades e competências de que precisarão para participarem ativamente da sociedade como cidadãos e contribuir para a sua evolução (OCDE, 2010, p. 354, sem grifo no original).

A equipe de avaliação da OCDE e as autoridades catarinenses partilham a preocupação de que os participantes do sistema educacional adquiram o conhecimento, a postura e as habilidades que os tornará flexíveis, adaptáveis e capazes de refletir e aprender sozinhos. A esperança é que consigam desenvolver habi-

\footnotetext{
${ }^{13}$ Os autores mostram que compreendem a dicotomia capitalista quando escrevem que as pessoas dependem das organizações para trabalhar e, desse modo, atingir seus objetivos individuais, e as organizações necessitam das pessoas para também alcançar seus objetivos.Assim, embora a tecnologia ofereça um grande diferencial competitivo no mercado, as pessoas são as que de fato fazem diferença na organização por possuírem uma ampla gama de competências a serem desenvolvidas e utilizadas para alavancar o sucesso organizacional.
}

lidades e competências transferíveis para atingir o seu potencial como cidadãos e contribuir ativamente para o desenvolvimento da sua sociedade nesta empolgante era de mudanças (OCDE, 2010, p. 355, sem grifo no original).

A avaliação da Organização para a Cooperação e Desenvolvimento Econômico OCDE (2010) traz um estudo do Banco Mundial que constata que a falta de competências básicas dos trabalhadores pode ter sido o principal obstáculo para o desenvolvimento livre de práticas inovadoras das empresas. Há uma clara responsabilização dos sujeitos trabalhadores pelo desenvolvimento econômico - por seu fracasso ou sucesso - e, torná-los competentes, significa educar para que a evolução e a flexibilização das relações de trabalho sejam garantidas.

Isso mostra que as necessidades do mercado de trabalho, seja a indústria, o comércio, a prestação de serviços, ainda direcionam os processos educativos como no início do século passado, agora camufladas pelas determinações dadas com nomes de competências.

\section{CONSIDERAÇÕES FINAIS}

No contexto de um sistema capitalista cada vez mais dominante e massificador do proletariado, a educação mesmo que tenha sido fundamentada em uma estrutura que separe quem é o empregado e quem é o empregador, através dos tempos, modificou seus ideais, e incorporou a ideia de retirar os sujeitos da situação de subalternidade, apresentando-Ihes como as estruturas sociais são incorporadas, e como o conhecimento científico pode conduzi-los a busca de direitos. 
Entretanto, mesmo com os embates feitos através dos tempos, atualmente a nova forma avançada do capitalismo, que é o neoliberalismo, tende a retroceder o pouco avanço que se conseguiu realizar, uma vez que os sujeitos continuam tendo seus direitos educativos atrelados às necessidades de um mercado de trabalho cada vez mais exigente e segregador.

As necessidades emanadas do atual Modo de Produção Capitalista influenciam sistematicamente as estruturas curriculares, políticas pedagógicas e diretrizes normativas que buscam determinar os processos educativos, sendo assim, a constituição de um ser humano integral ainda requer estudos, lutas e pressões dos movimentos populares da sociedade civil que façam frente a essas deliberações pautadas na fragmentação do trabalhador.

Embora a educação pareça dominada por interesses que não são os dos trabalhadores, entende-se que a reflexão sobre os processos de formação humana para além do Modo de Produção Capitalista é fundamental para que os sujeitos comprometidos com alguma mudança social se insiram em um horizonte de possibilidade, e essa reflexão passa necessariamente pela compreensão histórica que busca equacionar a atual conjuntura da educação com suas raízes nas concepções administrativas para a formação do trabalhador.

\section{REFERÊNCIAS}

ARROYO, M. G. O Direito do Trabalhador à Educação. In: MINAYO G., C. et al. Trabalho e conhecimento: dilemas na educação do trabalhador. 6. ed. São Paulo: Cortez, 2012. FAYOL, H. Administração Industrial e Geral: previsão, organização, comando, coordena- ção, controle. 10. ed. São Paulo: Atlas, 1994.

FRIGOTTO, G. Trabalho, conhecimento, consciência e a educação do trabalhador: impasses teóricos e práticos. In: MINAYO G., C. et al. Trabalho e conhecimento: dilemas na educação do trabalhador. 6. ed. São Paulo:Cortez, 2012.

GADOTTI, Moacir. Concepção dialética da educação: um estudo introdutório. 16. ed. São Paulo: Cortez, 2012.

GENTILI, P. Três teses sobre a relação trabaIho e educação em tempos neoliberais. In: LOMBARDI, J. C.; SAVIANI, D.; SANFELICE, J. L. (Orgs.) Capitalismo, trabalho e educação. Campinas: Autores Associados, 2002.

GERENCER, P. Vida e Obra de Taylor. In: TAYLOR, Frederick W. Princípios de Administração Científica. 8. ed. São Paulo: Atlas, 1990.

GIRARDI, D. M.; DALMAU, M. B. L. Administração de Recursos Humanos I. 2. ed. Florianópolis: Departamento de Ciências da Administração/UFSC,2012.

HARVEY, D. Espaços de esperança. 6. ed. São Paulo: Edições Loyola, 2013.

. O enigma do capital: e as crises do capitalismo. São Paulo: Boitempo, 2011.

HOBSBAWM, E. J. Mundos do trabalho: novos estudos sobre história operária. 3. ed. Rio de Janeiro: Paz e Terra, 2000.

KUENZER, A. Z. Ensino de 2o grau: trabalho como princípio educativo. São Paulo: Cortez, 1988.

LAFFIN, M. Trabalho, economia solidária e processos educativos. In: LAFFIN, M. H. L. F. (Org.). Educação de Jovens e Adultos, diversidade e o mundo do trabalho. Ijuí: Unijuí, 2012.

MARX, K. O Capital: crítica da economia política: Livro I: o processo de produção do capital. São Paulo: Boitempo, 2013. 
. Manuscritos econômicos-filosóficos. São Paulo: Boitempo, 2010. MARX, K.; ENGELS, F. Manifesto comunista. rev. São Paulo: Boitempo, 2010.

MONTAÑO, C.; DURIGUETTO, M. L. Estado, classe e movimento social. 3. ed. São Paulo: Cortez, 2011.

MORETTO NETO, L.; SCHMITT, V. G. H. Teoria Geral da Administração. 2. ed. Florianópolis: Departamento de Ciências da Administração/UFSC, 2011.

NOSELLA, P. Trabalho e educação: do tripulium da escravatura ao labor da burguesia; do labor da burguesia à poiésis socialista. In: MINAYO G., C. et al. Trabalho e conhecimento: dilemas na educação do trabalhador. 6. ed. São Paulo: Cortez, 2012.

. A Escola de Gramsci. 3. ed. São Paulo: Cortez, 2004.

NORONHA, O. M. Ideologia, trabalho e educação. Campinas: Alínea, 2004.

OCDE - Organização para a Cooperação e Desenvolvimento Econômico. Avaliações de Políticas Nacionais de Educação: Estado de Santa Catarina, Brasil. 2010.

RIBAS, C. C. Os dekassegui: uma outra face do toyotismo. 1998. Tese (Doutorado em Ciências Sociais) - Instituto de Filosofia e Ciências Humanas, Universidade Estadual de Campinas. Campinas, 1998.

SÁNCHEZ VÁZQUEZ, A. Filosofia da Práxis. 2. ed. São Paulo: Expressão Popular, 2011.

SHIROMA, E. O. O modelo japonês e o debate sobre qualificação e controle da força de trabalho. Perspectiva. Florianópolis, v. 14, n. 26, p. 173-186, 1996.

TAYLOR, F. W. Princípios de Administração Científica. 8. ed. São Paulo: Atlas, 1990.

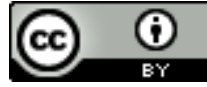

License information: This is an openaccess article distributed under the terms of the Creative Commons Attribution License, which permits unrestricted use, distribution, and reproduction in any medium, provided the original work is properly cited.

Artigo recebido em 11 de novembro de 2016.

Avaliado em 24 de novembro de 2016.

Aceito em 13 de dezembro de 2016.

Publicado em 28 de março de 2017.

\section{Como citar este artigo (ABNT):}

MECHELN, Morgana Zardo von; VIGANO, Samira de Moraes Maia; LAFFIN, Maria Hermínia Lage Fernandes. Educação no Modo de Produção Capitalista: as influências sofridas pelo sistema. Estação Científica (UNIFAP), Macapá, v. 6, n. 3, p. 51-61, set./dez. 2016. 